\title{
LA ECLAMPSIA A FINES DEL SIGLO PASADO
}

\author{
Dr. Fernando Sánchez Torres*
}

Leyendo la tesis de grado del doctor Campo Elías Corredor, publicada en Bogotá en 1892 y titulada "Contribución para el estudio de los partos difíciles: Eclampsia puerperal", encontramos conceptos y procederes tan interesantes como curiosos que permiten algunos comentarios en torno suyo. El doctor Corredor, si no hizo una aportación original al problema apasionante de la eclampsia, nos legó, en cambio, un estudio completo de la enfermedad, que resume las ideas imperantes en las últimas décadas del siglo pasado. Aún más, pensamos que es de las primeras contribuciones en Colombia al tema de la toxemia gravídica pues, hasta donde hemos buscado, sólo le antecedió la de Pablo E. Molina, publicada según Pedro María Ibáñez entre 1873 y 1876. A pesar de que no nos fue posible encontrar dicha publicación creemos que no fue tesis doctoral pues Molina recibió su grado en la Facultad de Medicina de la Universidad Nacional en 1872. De todas maneras, en el lapso corrido entre una y otra, los hechos nuevos en el terreno de la eclampsia debieron de ser muy pocos; por lo tanto hemos tomado el estudio del doctor Corredor para juzgar lo que sobre dicha enfermedad sabían nuestros médicos finiseculares.

Antes de entrar en materia, prudente es que echemos una ojeada al medio que rodeaba a Campo E. Corredor para poder interpretar con imparcialidad lo consignado por él en su tesis.

Corredor era, en 1891, practicante interno en el Servicio de Maternidad y Clínica Infantil del Hospital Civil de Bogotá, o sea el Hospital de San Juan de Dios. Al decir de Cordovez Moure dicho hospital tenía entonces una sala de maternidad y un orfelinato fundado por el arzobispo Arbeláez. El edificio tenía capacidad para asistir a 3.500 enfermos en el año. El mismo Cordovez afirma que "la farmacia, ropería y lavado al vapor, alimento, aseo y asistencia médica de los enfermos, son superiores a todo elogio", pero - añadimos nosotroses de imaginar que la asistencia obstétrica fuera un verdadero drama, no por la calidad de quienes la prestaban, sino por la índole misma de las mujeres que acudían en demanda de atención, ya que casi todas eran casos complicados por las comadronas. Además, la sepsis se enseñoreaba del pequeño servicio, hasta tal extremo que tuvo que ser cerrado en enero de 1899 pues "tantas madres murieron cuantas había en la clínica". Por otra parte, era la única institución que disponía de un servicio gratuito de

* Profesor Asistente del Departamento de Obstetricia y Ginecología. Facultad de Medicina (Universidad Nacional). 
maternidad para una ciudad que contaba con 135.000 habitantes. Según datos estadísticos se atendían de 30 a 35 partos al mes.

Eran docentes de obstetricia los doctores José María Buendía, Leoncio Barreto, Carlos Clopatofsky y Elberto de J. Roca, todos figuras eminentes de nuestra medicina. Hay que aceptar que los conceptos del doctor Corredor eran los mismos que sus maestros, pues dice en el preámbulo: "Me limito a vulgarizar los principios consignados en las obras y periódicos recientes, las ideas emitidas en la cátedra por el señor profesor Barreto, y, por último, los hechos recogidos en la práctica hospitalaria del servicio de maternidad, tan hábilmente dirigido por el doctor Buendía".

A medida que vayamos recorriendo el estudio del doctor Corredor podremos enterarnos de las teorías y procederes de la época, venidos de Europa, particularmente de Francia.

La sinonimia utilizada para mencionar la eclampsia, pone de presente la confusión reinante sobre la etiología de la enfermedad: convulsicnes urémicas, epilepsia aguda, encefalopatía brightica, encefalopatía albuminúrica, espasmos renales, distocia convulsiva, etc. En los días que corren toda esa serie de términos quedó relegada por la simple denominación "eclampsia", cuya sencillez compensa la ignorancia que tenemos acerca de ella.

Desde un principio el autor se inclina por la teoría etiológica de Bouchard, la cual le permite definir así a la entidad: "La eclampsia es una toxemia de origen renal con perturbaciones intelectuales, sensitivas y motoras. Es una intoxicación convulsiva. En los casos que he visto en el hospital, la anuria no ha faltado ni una sola vez. De manera que la eclampsia está caracterizada por una lesión renal y por anuria; en definitiva, por una retención, o mejor dicho, una reabsorción de los elementos de la orina". En la actualidad se acepta que en la toxemia predomina una nefropatía, es decir que el riñón es el órgano que sufre dos los primeros y en forma constante el impacto de la enfermedad. Otra teoría, la septicémica, defendida por Delore, Smellie, Lachapelle y Bouteillox, es refutada por el doctor Corredor con muy buen juicio. La tercera teoría en boga, la nerviosa, sustentada desde 1851 por Marchal, afirmaba que la eclampsia dependía de un edema cerebral producido por la enfermedad de Bright, opinión que niega el autor de la tesis que comentamos. Hoy se sabe que la eclampsia, o convulsiones del síndrome toxémico, no es más que una encefalopatía hipertensiva causada por una retención hidrosalina, consecuencia de la nefropatía existente. Como vemos, tanto la teoría de Bouchard como la de Marcha! tienen cabida, mutatis mutandis, dentro de la actual concepción fisiopatológica de la eclampsia.

Entre las causas predisponentes de la enfermedad cita el clima, el género de vida, la primiparidad, la preñez gemelar, la herencia y la edad. Refiriéndose al clima presenta un cuadro comparativo: en Bogotá aparece una eclampsia por cada 115 partos, en Francia una por cada 287, en Suecia una por cada 167 y en Alemania una por cada 665. En cuanto al género de vida dice que "las casadas son menos predispuestas que las solteras y no es raro ver aparecer la enfermedad en gentes pobres, que viven en partes húmedas". De las causas señaladas todas tienen validez para nosotros, excepto la de la herencia. 
En aquel entonces se creía que la eclampsia se heredaba. "En el servicio del profesor Buendía -anotaoperé con el fórceps una mujer que había sufrido veinte ataques eclámpticos; la madre sucumbió por una hemorragia uterina producida por la extracción de la placenta; el niño lo extraje vivo: era pequeño, y presentó convulsiones que duraron dos días. Lo hice cuidar por una buena nodri$z a$, y quince días después se lo entregué al padre, sano y robusto". Es fácil deducir que esos casos de "eclampsia heredada" eran solo consecuencia de la anoxia que ocasionan las crisis convulsivas maternas, junto con el traumatismo obstétrico.

Como buenos seguidores de la escuela francesa, nuestros antiguos médicos fueron maestros en las descripciones clínicas. Su ojo clínico reemplazaba en buena parte los aparatos que empleamos hoy. Tengamos en cuenta que en la época y lugar que nos ocupan no se utilizaban ni el tensiómetro ni el oftalmoscopio.

La sintomatología se dividía en prodromos, convulsiones y coma. El prodromos se identificaba por cefalalgia, perturbaciones de la visión, "que son comunes, las más notables y las que reclaman un examen más atento de la parte del práctico. Si el clínico levanta con sus dedos los repliegues de la conjuntiva, verá una equimosis serosa. El ojo es vivo, animado, brillante; presenta los caracteres del estado que los ingleses Ilaman Bright's eye. Revela un edema de la conjuntiva, manifestación precoz de las lesiones renales... El ojo de Bright, es pues, un revelador anticipado de las alteraciones patológicas del filtro renal". Refiriéndose al dolor epigástrico anota el doctor Corredor que "cuando esta sensación aumenta, el acceso no tarda en presentarse". Si juntamos la sintomatolo- gía prodrómica señalada (cefalalgia, perturbaciones visuales y epigastralgia) queda conformado lo que conocemos con el nombre de "inminencia de eclampsia", o para otros "preeclampsia grave". "Me he extendido sobre los prodromos -afirma- porque desde que se observen, la prudencia $m a n d a$ temer el acceso eclámptico y establecer una medicación preventiva".

La descripción que hace de las crisis convulsivas es exacta, gráfica y detallada. Hablando de la apnea que acompaña a la fase tónica, dice: "La cara se cianosa, las yugulares se congestionan, las mejillas son bultuosas, y como los miembros se ponen rígidos y la respiración se suspende, el observador, aterrado, tiene la visión de la muerte ante sus ojos". En verdad, todo el que asiste por primera vez a una crisis eclámptica recoge la misma impresión. "El globo del ojo empañado rueda en las órbitas, pero por intervalos al mirada se enciende y brilla con un resplandor siniestro, que dura un solo instante para extinguirse luego; de ahí el nombre de la enfermedad, eclampsia, lucir, brillar de repente como el rayo". Este sentido que le da el doctor Corredor a la palabra "eclampsia", basado únicamente en la luminosidad del globo ocular, es simplemente acomodaticio, pues si es cierto que significa por su etimología griega "hacer explosión", la enfermedad se llamó así por el hecho de que los antiguos veían aparecer las crisis convulsivas en forma súbita.

En cuanto al pronóstico dice que la mortalidad materna entre los franceses es del 50 por 100; entre los ingleses del 25 por 100 y entre los colombianos del 60 por 100. "La muerte viene rara vez en el período convulsivo, al contrario durante el coma es muy frecuente, pues entonces apa- 
recen complicaciones pulmonares: edema, congestión, derrames serosos, hemorragia de los vasos cerebrales y de las meninges".

Respecto a los conocimientos anatomopatológicos agrega que "de las autopsias que he practicado en el anfiteatro de mujeres muertas $d e$ eclampsia, he encontrado siempre alteraciones renales, del cerebro y de la medula espinal... Los riñones presentan las alteraciones de la enfermedad de Bright, en todas sus formas... En algunos casos un solo riñón es invadido". Se deduce de lo anterior que únicamente tenía en cuenta los hallazgos macroscópicos; es curioso, por eso, que no le hubieran llamado la atención los cambios hepáticos, tan notorios en todas las pacientes fallecidas por toxemia.

Los recursos que se utilizaban para combatir la eclampsia eran unos médicos y otros quirúrgicos. Como profilaxis se recomendaba la dieta láctea, el yoduro de potasio y la digital. $\mathrm{Si}$ estas medidas no combatían las manifestaciones prodrómicas, se recurría a la provocación del parto artificial - conducta propuesta por Tarnier - en base a las siguientes condiciones:

“1a. Que la preñez haya llegado al fin del octavo mes, para que el niño pueda vivir;

2. Que la albuminuria haya persistido con tenacidad, o haya aumentado, y que la enferma sienta algunos de los signos prodrómicos;

3. Que la mujer sea primípara o que haya tenido accesos en los partos anteriores;

4. Que hayan encallado todos los medios médicos, inclusive la sangría.
Con estas condiciones bien precisas se procede a provocar el parto según las reglas del arte".

Según dichas reglas la provocación del parto se conseguía perforando las membranas, 0 utilizando el colpeurínter, el sondeo del cuello uterino, las duchas vaginales calientes, la estimulación suave y sostenida del cérvix por medio del dedo del partero, medidas las cuales desencadenaban las contracciones y dilataban el cuello "lo suficiente para introducir el fórceps o la mano y terminar el parto con la extracción o la versión".

El tratamiento médico comprendía, como ahora, medidas de orden general y el empleo de fármacos. Las enfermas se observaban con cuidado y se les evitaba toda excitación. Esto, para nosotros, es uno de los detalles sobresalientes en el manejo de las paciente eclámptica; hace ocho décadas para el doctor Corredor también lo era. "Se practica el tacto -decíay se ausculta lo estrictamente necesario para no provocar los accesos".

La flebotomía, incluída entre las medidas más importantes, consistía en la extracción de 500 a 2.000 centímetros de sangre. Lachapelle, Depaul y Charpentier, fueron grandes defensores del sistema.

Los fármacos de que se echaba mano eran la pilocarpina, la medicación purgante (aguardiente alemán, jalapa, calomel), el bromuro de potasio - propuesto por Hoyer-y el nitrito de amilo. Pero sin lugar a duda, eran el cloral, el cloroformo y el opio y sus derivados los que más empleo tenían. El cloral, preconizado por Bouchut, se suministraba por vía rectal y según Corredor, "de todos los métodos es el que parece haber dado los mejores resultados". El cloroformo, aconsejado por Richet desde 
1848, se usaba depositando treinta gotas sobre una compresa para que la enferma inhalara sus vapores. El opio, del que fueron buenos defensores Naegele, Stolz y Olshausen, tenía también gran acogida: "El profesor Buendía usa la tintura asociada al tártaro estiviado, y ha obtenido éxitos brillantes en la práctica civil y hospitalaria".

Luego de esta presentación de la tesis del doctor Corredor, los lectores, en particular aquellos que se han interesado por el intrincado problema de la toxemia gravídica, sacarán como deducción, seguramente, que a pesar de todos los años que han corrido y de todos los esfuerzos puestos para combatir y vencer la eclampsia, continuamos, en algunos aspectos, viviendo los finales del siglo pasado.

Para terminar, copiamos dos de los casos clínicos que sirvieron de base al estudio de Campo E. Corredor.

"El 17 de Agosto de 1892 entra al servicio de Maternidad Catalina Olaya, mujer de buena estatura, de constitución vigorosa y de temperamento sanguíneo. Los deudos la traen sumergida en un coma profundo, y refieren que desde hace un mes tiene edema en los miembros inferiores, que en la noche anterior tuvo cinco - seis accesos convulsivos y por último que se halla en el noveno mes del embarazo.

Mientras la examino estalla un ataque de eclampsia sumamente fuerte, calma el período convulsivo, pero queda cianosada y sin respiración. Tiene un edema general, el vientre es muy voluminoso, llega al reborde de las falsas costillas; la cabeza fetal se halla en la fosa ilíaca izquierda, las pequeñas partes al lado derecho, los ruidos del corazón del feto se perciben por la auscultación al lado izquierdo, debajo del ombligo. El tacto muestra un cuello alto, que apenas permite la introducción de la última falange del dedo índice. Se diagnostica un embarazo, una presentación cefálica, una eclampsia y un feto vivo. Se nota que no hay principio de trabajo, el cuello está cerrado. Se procede a tratarla.

Mi amigo Nicolás Buendía extrae 500 gramos de sangre de la basílica izquierda. Los accesos ceden por algún tiempo, pero a las seis de la tarde estallan de nuevo y con una intensidad muy grande. La cloroformizo hasta las diez de la noche y ceden los ataques; examinando el cuello no presenta ninguna dilatación.

A las once de la noche, no obstante el cloroformo, se repiten las convulsiones; son muy intensas y la asfixia que sigue a los acceso; es muy marcada. El cuello empieza a dilatarse. Mi amigo Manuel Mejía me acompaña y resolvemos operarla. Fuí en busca del profeser Buendía, y no estaba en la casa. Cuando vo! ví la hallé sumergida en un coma profundo; el cuello está apenas dilatado, pero felizmente es bastante dilatable. La posición de la cabeza es la primera de Naegele. Mejía se encarga del cloroformo y yo del fórceps. La cabeza fetal está alta y acompañada por una mano; la apiicación del instrumento es larga y difícil. Los ruidos redoblados del corazón del niño han desaparecido. Después de varias tracciones logramos extraerlo; se le dan todos los cuidados pero no vuelve a la vida. Se saca la placenta por expresión.

Tiene dos ataques más en la noche; al día siguiente tiene dos, luego cae en un coma profundo, que dura treinta y seis horas. Al tercer día se levanta del lecho, vocifera, recorre la sala apresuradamente, tiene accesos de manía puerperal durante cuatro días.

El 2 de Octubre sale del servicio en perfecto estado de salud".

Caso No VIII. El 24 de Septiembre de 1891 entró al hospital, al servicio del profesor J. M. Buendía, una mujer de 25 años de edad, temperamento linfático, buena estatura y atacada de uretritis blenorrágica. El día anterior, a las 12 de la noche, estallaron grandes convulsiones, por las cuales fue llevada a la sala de Maternidad.

El profesor Buendía la examinó, y diagnosticó una eclampsia. Se nota el vientre aplanado y con aumento de volumen. El límite superior de la matriz está colocado cuatro dedos debajo del apéndice esternal. Los ruidos redoblados del feto se oyen al lado izquierdo. La extremidad cefálica se encuentra muy alta; el cuello rígido permite apenas introducir la pequeña falange del índice. Se notan algunas contracciones débiles y arrítmicas del útero.

Tratamiento. Inmediatamente el profesor Buendía procedió a dilatar el cuello por medio de duchas de agua, a 40 grados de temperatura; a las dos de la tarde se introdujo el colpeurínter, en la dilatación producida por el dilatador de Pajot. El colpeurínter se llenó de agua a 40 grados y se dejó hasta las cuatro 


\section{FERNANDO SANCHEZ TORRES}

de la tarde. A las cuatro y media se hizo el cateterismo para extraer la orina que salió en pequeña cantidad. El profesor Buendía colocó el fórceps $y$ extrajo, con rapidez, un feto muerto.
Enero-Febrero 1969 Rev. Col. Obst. y Ginec.

La operación fue tan bien hecha que no hubo desgarradura del periné ni hemorragia. La matriz se retrajo muy poco. La enferma entró después en un coma profundo y murió a las cinco de la tarde". 